\title{
A Qualitative Study among Refugee Children with Anxiety in Kuala Lumpur, Malaysia: The Effect of Child-Centred Play Therapy on the Social-Emotional Development
}

\author{
Melika Taheri, Mariani Mansor \& Zainal Madon
}

To Link this Article: http://dx.doi.org/10.6007/IJARBSS/v11-i12/11787

DOI:10.6007/IJARBSS/v11-i12/11787

Received: 21 October 2021, Revised: 24 November 2021, Accepted: 11 December 2021

Published Online: 28 December 2021

In-Text Citation: (Taheri et al., 2021)

To Cite this Article: Taheri, M., Mansor, M., \& Madon, Z. (2021). A Qualitative Study among Refugee Children with Anxiety in Kuala Lumpur, Malaysia: The Effect of Child-Centred Play Therapy on the Social-Emotional Development. International Journal of Academic Research in Business and Social Sciences, 11(12), 407417.

Copyright: (c) 2021 The Author(s)

Published by Human Resource Management Academic Research Society (www.hrmars.com)

This article is published under the Creative Commons Attribution (CC BY 4.0) license. Anyone may reproduce, distribute, translate and create derivative works of this article (for both commercial and non0-commercial purposes), subject to full attribution to the original publication and authors. The full terms of this license may be seen at: http://creativecommons.org/licences/by/4.0/legalcode

Vol. 11, No. 12, 2021, Pg. 407 - 417

Full Terms \& Conditions of access and use can be found at http://hrmars.com/index.php/pages/detail/publication-ethics 


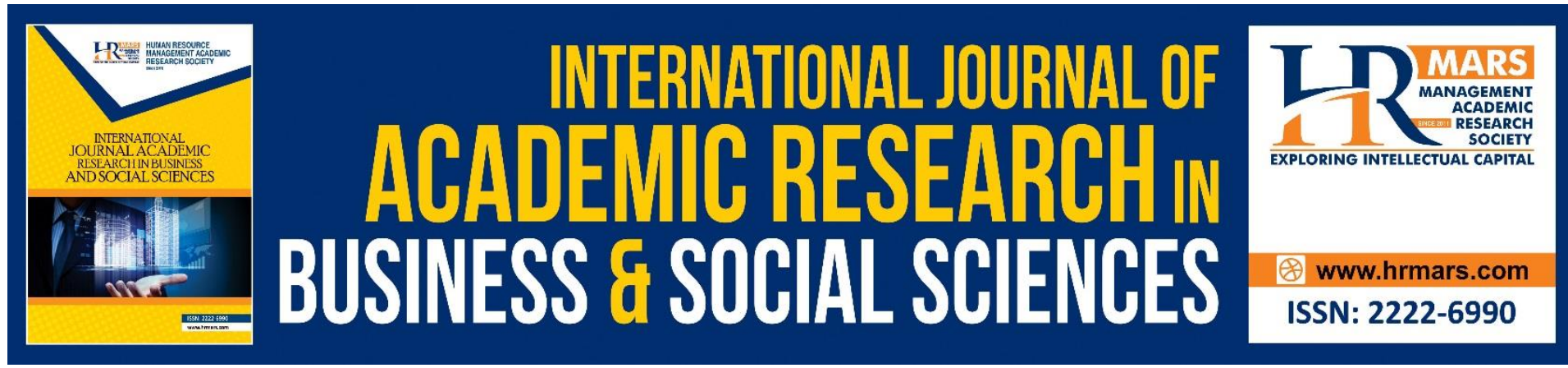

\title{
A Qualitative Study among Refugee Children with Anxiety in Kuala Lumpur, Malaysia: The Effect of Child-Centred Play Therapy on the Social- Emotional Development
}

\author{
Melika Taheri ${ }^{1,2}$, Mariani Mansor ${ }^{1} \&$ Zainal Madon $^{1}$ \\ ${ }^{1}$ Department of Human Development and Family Studies, Faculty of Human Ecology, \\ Universiti Putra Malaysia, 43400 Serdang, Malaysia, ${ }^{2}$ Faculty of Behavioral Science, School of \\ Psychology, University of Newcastle, 2308, Callaghan, NSW, Australia \\ Email:melika.taheri@uon.edu.au,mariani@upm.edu.my,zainalm@upm.edu.my
}

\begin{abstract}
Healing a sense of self-acceptance and independence among vulnerable groups via developmental methods is a matter of concern by developmental psychologists. Additionally, Malaysia, as a bridging country, is involved in refugees' journeys. Thereby, this paper is focused on findings from a study carried out on refugee children. This study aimed to investigate the psychosocial development of refugee children with anxiety through the Child Centered Play Therapy (CCPT) process. Nine Farsi speaking refugee children between the age ranges of 8 to 12 in Kuala Lumpur, Malaysia, have participated in 90 CCPT sessions in Sahabat Support Centre. Data were collected on each child's CCPT session via individual participant observation of the researcher, field notes, video recording and photos taking, alongside participants' weekly journal entries. Thematic analysis showed that the CCPT process revealed improvement in self, social and emotional development among the respondents. This study proved that CCPT is an effective tool to elevate the suffering of children in one of the most vulnerable group, such as the refugees. Community workers, school teachers, counsellors, and therapists are able to utilize play therapy as an appropriate medium to elevate the children's suffering and meet their fundamental psychological needs accordingly.
\end{abstract}

Keywords: Community, Child Centred Play Therapy, Children, Refugee, Social-Emotional Development

\section{Introduction}

The refugee population has been dramatically raised throughout the past few decades due to wars, natural disasters, and economic crises. The United Nations High Commissioner for Refugees (UNHCR) (2016) reported that about 21.3 million refugees were around the globe, and more than half were children. Malaysia, as a bridging country (second phase-during migration), contained 150,669 refugees, and 35,069 are children below 18 years old (UNHCR, 2016). 
Refugee children have gone through different hardships. Therefore, they have developed unique mental and physical health needs raised from both their experiences and as a reflection of their journey. Their hardships, including experiencing war and its induced trauma, separation from their families, lack of governmental protection or social support, frequently exposed them to exploitation, trafficking, and abuse (United Nations Children's Fund, 2012) and finally, adapting to a new place and culture, learning a new language which detrimentally influences the child's wellbeing (Hands et al., 2015) and elevates the risk of severe psychological difficulties (Bronstein \& Montgomery, 2011). Children did not automatically go through physical and psychological screening, which might address childhood developmental concerns (Surin, 2016), and the process consequently affects their adulthood. Therefore, children's developmental wellbeing is vital to avoid further complications and its related challenges for themselves as well as the community and the society.

Refugee children will not necessarily experience impairment, as various cultural, familial, and experiential factors may boost their resilience and contribute to improving psychological functioning following trauma. Developing and utilizing a practical, effective method to improve refugee children's psychosocial wellbeing, including social and emotional development, is serving the purpose and its importance. In this regard, Child Centered Play Therapy (CCPT) as an available therapeutic tool for children has shown a positive effect on children's different developmental aspects, particularly on social and emotional aspects, such as improving social skills (Watson, 2007) and enhancement in self-concept (Tydall-Lind et al., 2001) and it has positively contributed to healing the emotional complications among children in different contexts (Althy, 2005).

CCPT as a participatory tool engaged children to be the centre of the process and in control by focusing on playing itself that helps children to self-exploring of emotions, thoughts, and behaviors in a safe and supportive environment along with professional help to revive their individual developmental process without any force or instruction which leads them to become a healthier individual (Landreth, 2012). CCPT as a tool gives a number of options in terms of activities to increase the likelihood of preferred options that suit the child's preferred communication channels through breaking down the power relations between children and adults (Barker and Weller, 2003; Einarsdottir, 2005) result in their social and emotional development. Therefore, this paper presented a qualitative study carried out on the personal experiences of Farsi speaking refugee children with anxiety, through the CCPT process, in Kuala Lumpur, Malaysia. The study objectives were to explore the personal perspective of refugee children with anxiety on their inner experiences through the CCPT process and to describe the effect of the CCPT process on the children's social-emotional development.

\section{Method}

\section{Participants}

The purposive homogenous sampling method was adapted to identify suitable respondents, i.e., children with anxiety between the ages of 8 to 12 years old. A homogenous sample of Farsi speaking children with similar background. and conditions were selected with the referral and assistance from their school counsellor and the Sahabat Support Centre's medical doctors and registered counsellors. The potential cases referred by Sahabat Support Centre went through a pre-evaluation screening process to achieve suitable homogenous samples. 
The pre-evaluation obtained from Spence Children's Anxiety Scale (SCAS), which contained a 44-item self-report questionnaire, revealed children's anxiety in the children with age range between 8 to 15 years old. Based on the SCAS manual, T-score $=60$ is the cut-off score suggested, which were based on age and gender to identify as a normal or elevated level of anxiety. The T-score under 60 was notified to be normal, and score above 60 is categorized as elevated or high level of anxiety (Spence, ND). So in this study, the referred participants for play therapy sessions were selected from children with high or elevated level of anxiety.

\section{Data Collection and Analysis}

Prior to the data collection, permissions were obtained from multiple sources such as the UPM ethics committee, UNHCR Malaysia and Sahabat Support Center. The screening was then carried out to identify potential participants while cross-checking the criteria with the school counsellor, the medical doctors, and other registered counsellors on their referral cases. Guardians' written consent and children's verbal assent were obtained to proceed with the CCPT process and data collection.

The researcher, as the play therapist, triangulated the screening process, the data collection methods and the reviewers point of views, to avoid any biases. All nine children went through 10 weekly sessions of 35 minutes individual CCPT sessions, which were held in the Sahabat Support Centre's counselling playroom. Each child's strengths and his/her complications were analyzed, besides their verbal and nonverbal behaviors such as facial expression, body posture, and the relationship with the play therapist, to explore their social and emotional development.

Several different techniques of qualitative data collection were implemented, such as participant observation, field-notes and field-pictures, video-taped, in-depth interviews and journal entries for each individual case. The information were interpreted based on the social-emotional development domain such as social competence, emotional competence, behavior problems, and self-regulation as the components of social-emotional development and their related criteria (Halle, Kristen, \& Darling-Churchill, 2016). All the sessions were video-taped and later transferred to an external hard disk. Watching and evaluating play therapy sessions on video-tapes provided the opportunity to trace any social-emotional developmental progress based on each session.

A meeting between the researcher and the reviewer was conducted to validate each child behavior, expressed feelings, and activities; the interpretation of the behaviors, expressed feelings, and activities in relation to the social-emotional criteria and domains after each session to double-check the field-notes with the video-tapes. Through the process, few sessions were taken randomly to be observed, interpreted, and coded separately and then compared the outcome to meet greater validity. A reviewer is a qualified play therapist who has done supervision over many clinical therapeutic sessions in play therapy projects. Basically, in this study, the reviewer act as a supervisor and her role is to review, provide support and advice during the play therapy clinical work. Issues relating to reporting case sessions, therapeutic and ethical decision are among the consultation referred to the reviewer. The reviewer also participated in evaluation to determine the termination signs in each individual case. 
The last data collection technique was respondents' journal entries. Throughout all the sessions, respondents were required to keep a personal journal, i.e. writing or drawing their personal experiences and feelings about each session and brought it to the following session and handed it to the researcher. Children ages nine years and older can contribute valid information about their own feelings, experiences, behavior, and physical symptoms through many of the traditional data collection methods, such as diaries, in-person interviews, written surveys, and computer-based surveys (Rebok et al., 2001). In this study, as CCPT is led by children, they tend to draw, write, and colour in their journal entries. All these journal entries are also documented in the external hard disk individually. Another certified child play therapist, who was earlier trained and briefed about the study, also assisted in the research as an additional rater. Her task was to check the gathered data monthly with the referral admin in the Sahabat Support Centre to cover up any additional data and suitable information as they had each child background information and their current circumstances. The additional rater helped in triangulating the data collected.

Manual thematic analysis was used due to its focus on discovering the sequence of socialemotional development of children in the CCPT process under study. In this process, raw data (field notes, field pictures, etc.) as descriptive notes and then reflective notes were gathered and organized individually. Each case notes on each session were coded based on predetermined criteria and domains (Halle et al., 2016). The extracted codes were merged into subtheme and themes. Themes were analyzed for each individual case and across different cases. Data from respondents' journal entries were also analyzed.

To fulfil the study objectives, the researcher traced each respondent personal feelings and experiences over time for every single case based on their own perspectives in each individual journal entry. Data from respondent's weekly journal entries were then categorized and grouped into themes and subthemes in relation to social and emotional development. The children's inner-feelings and experiences reflected through the CCPT process gave their personal insight into the study. Data on each individual case obtained through video taped sessions, field notes and pictures coded were also analyzed to assess their social-emotional development. To ensure that analysis is accurately done, each session was checked by another professional play therapist reviewer and a registered counsellor to ensure the trustworthiness of the collected data. Then the coded information was categorized in a larger context as a subtheme. The subthemes were categorized into a bigger concept named as themes in each session individually. These themes and subthemes were the final progressive social and emotional development changes that participants have experienced through the CCPT process.

\section{Findings and Discussion}

\section{Summary of Findings: Participants' Inner Experiences through CCPT Process}

In line with the study objective, respondents' inner experiences through the CCTP process were recorded and analyzed through three phases. The refugee children with anxiety shared their inner experiences differently, and this was grouped into three main domains, i.e. sharing their feelings, reflecting on the play therapist, and reflecting on themselves. As they experienced different phases, from the initial to the final phase, their feelings and their reflections have changed naturally. From experiencing a mixture of positive and negative emotions such as worry and happiness in the first phase, they experienced more intensified 
feelings such as anxiety and pleasure in the middle phase and finally, they experienced the purely positive sense of relief and greatness in the final phase based on the extracted themes in each phase, as summarized in table 1 . Sadness is the only negative emotion expressed in the final phase, but their sadness was expressed as a termination sign (Landreth, 2012). The emotional improvement from the initial phase to the final phase was pointed by the respondents. The vague emotions in the initial phase got expressed on a deeper level through the middle phase, as pointed by the children.

In the CCPT process, getting in touch with self and receiving positive regard through a supportive relationship played a significant role in children's progress (Landreth, 2012). Teachers and peers played a significant role. In their developmental stage, children learn how to read, write and do things themselves. In the playroom, respondents were alone, so the absence of peers shifted their attention toward the play therapist. They shifted their attention, but were self-protective at the beginning. In the initial phase, respondents mostly focused on the play therapist, observing and reflecting both her actions and characteristics through the initial phase as the outcome of their precise observations. They evaluated the play therapist to either trust her or avoid her. As one of the characteristics of play therapist itself, unconditional love and support need to be the greater part of the therapeutic journey (Landreth, 2002). Respondents highlighted positive characteristics such as being nice, kind, and calm in the initial phase as the positive side of the play therapist's role. Also, they referred to her actions as non-dominant and culturally similar. Later, in the middle phase, children opened themselves emotionally to receive positive regard through the CCPT process, which they highlighted in their journal entries. In the final phase, children found themselves happy and secure through the CCPT journey that facilitated them to express a sense of gratitude toward the play therapist. Observing, communicating and interacting with the play therapist as an adult, highlighted the aspects of social-emotional bond developed through the CCPT process. The play therapist helped children to express their various emotions and experienced positive regards in a secure and supportive environment.

Each child goes through the process at their own rate. So, the changes in their behavior indicated different phase. All the respondents went through 10 sessions of individual CCPT, as CCPT preferred more than 8 sessions, less than 12 sessions (Landreth, 2012). In this study, 10 weekly 35 minute sessions individually took place due to preference of participants. As a play therapist, the researcher met the respondents individually to focus on their needs and the medium of play. Each child's strengths and complications were analyzed, beside on their verbal and nonverbal behaviors such as facial expression, body posture, and relationship with the therapist to explore social and emotional development. While exploring and playing with the toys provided, children showed their emotions through their facial expression, using words to communicate and talked on behalf of toys in playing scenes. They externalized their feeling through their behavior as an action, making sounds and using words. The certified play therapist follow the child instruction in playroom and reflected their observable feelings, and behavior accordingly to help children regain their inner power and used their inner resources to solve their personal conflicts. Initial behavior and repetitive behavior were signs in playing scenes which facilitated the play therapist to follow each child developmental journey (Landreth, 2012). Although there is no specific protocol to follow, there are special training courses for individuals to be trained as a certified play therapist. 
The last phase in the CCPT process is the saturation point. In CCPT, saturation is referred to as the termination points, which indicate the final phase. This termination point for each children (respondents) varies individually. In CCPT process, the focus point is on participants not on symptoms. Therefore, the appearance of functional process for the individual is the main goal (Ray, 2011). Children themselves showed few obvious signs of termination session in CCPT. They were about to bring the relationship to a close (final phase) by standing around the playroom, no longer interested in toys, being uninvolved, play slowly, and declared that they have nothing to do. There are also few non-verbal observable points to finalize the process (Landreth, 2012, p.359). Respondents showed the termination signs as their saturation point in sessions final phase. The evaluation was done according to the field notes, field pictures and video typing which collected through participant observation of the researcher. The reviewer also participated in evaluation to determine the termination signs in each individual case. Although children presented their saturation points differently, guardians tended to send them till the $10^{\text {th }}$ session. Therefore, the total sessions for children were 90 CCPT sessions.

The final reported experiences of refugee children through the CCPT process were based on their own journal entries, i.e. about how they reflected on themselves through the different continuous phases. Children were focused on themselves as a meaningful part of their journey. They shared how joyful they felt while being understood by another person in a similar language at the beginning. They also pointed, they experienced enjoyable engagement with toys and the play therapist through the CCPT process. The refugee children led themselves to experience self-awareness as well as positively expressed themselves through the enjoyable engagement with someone who understood them and shared positive regard with them. Children were amazed by experiencing new feelings and new ways of emotional release through the CCPT process. In the final phase, the emotional labelling and emotional recognition through being creative assisted children to overcome their initial negative feelings. Knowing the new dimensions of self was noted in developing a sense of self in this process. Table 1 below showed a summary of highlighted domains from refugee children's inner experiences through the CCPT journey.

Table 1: Summary of Participants' Inner Experiences Through CCPT

\begin{tabular}{|c|c|c|c|}
\hline Themes & Initial phase & Middle phase & Final phase \\
\hline Feelings & $\begin{array}{l}\text { - Worry } \\
\text { - Fun } \\
\text { - Happiness } \\
\text { - shyness } \\
\end{array}$ & $\begin{array}{l}\text { - boredom } \\
\text { - calmness } \\
\text { - pleasure } \\
\text { - anxiety } \\
\end{array}$ & $\begin{array}{l}\text { - relief } \\
\text { - greatness } \\
\text { - sadness }\end{array}$ \\
\hline $\begin{array}{l}\text { Reflecting on } \\
\text { others }\end{array}$ & $\begin{array}{l}\text { - characteristics } \\
\text { - actions }\end{array}$ & $\begin{array}{l}\text { - positive regard } \\
\text { (relationship) }\end{array}$ & $\begin{array}{l}\text { - sense of } \\
\text { gratitude }\end{array}$ \\
\hline $\begin{array}{l}\text { Reflecting on } \\
\text { self }\end{array}$ & $\begin{array}{l}\text { - being understood } \\
\text { - enjoyable } \\
\text { engagement }\end{array}$ & $\begin{array}{l}\text { - awareness } \\
\text { - creative } \\
\text { expression }\end{array}$ & $\begin{array}{l}\text { - emotional } \\
\text { recognition } \\
\text { - creativity }\end{array}$ \\
\hline
\end{tabular}

Summary of Findings: Respondents' Social-Emotional Development through CCPT Process Through the CCPT process, respondents experienced a range of changes in their psychosocial development, i.e. on their self, emotion and social development. Interacting with the play 
therapist helped them to express their dependency and their lack of self-concept freely. Due to the lack of self concept and the available inner conflicts, children tend to focus more on the external environment. They attempted to control their surroundings excessively. The feeling of inferiority played a significant role in this area. Children projected their own inner feelings of inferiority to the outer world. They tried to control the external world to fix the inner emotions by feeling industry even for a short period. For instance, they were aware of other children even without knowing them, and they tend to engage them in their own play scene. This process referred to having a game with an absent competitor, and the child made the opportunity to be a winner anyway.

In the next phase, the intensity of emotions helped them to go through the self-discovery process. Participants mostly have experienced role confusion due to the lack of sense of belonging to the new country and uprooted from the so-called home environment (the country of origin). Through the CCPT process in the middle phase, they received positive regards, which they highlighted through their inner experiences. It facilitated them to be courageous and walked into the self-discovery process. In the self-discovery process, they creatively explored different aspects of self. Few of them pointed their weaknesses, and few others highlighted their disregarded strengths. Recognizing their abilities and shortcomings offered them a sense of mastery over the tasks which they felt strong to accomplish. Being skilful in a task nurtured the competency feeling and also, the industry feeling in refugee children.

The sense of mastery affected them to balance their excessive control over the outer environment progressively. The tendency to be disorganized and forgetful as a highlighted point in refugee children emphasized the new balance in their developmental progress. These children tended to be perfect, acted perfectly, and excessively organized in the initial phase as indicators of perfectionism. When there was a match between their perfectionistic personal standards and their actual performance, they experienced self concept enhancement. On the other hand, when actual performance and self imposed high standards are incongruent, they had a poor self concept (Choy \& Mclnerney, 2006). These indicators of perfectionism were related to the poor self-concept in participants. They shifted their attentions from the outer environment to their inner selves, thus from excessive external control to experience the tendency to be disorganized and forgetful. In further steps, children experienced empathy toward others while experiencing their inner worlds. They became aware of other people's emotions while simulating with them through role play and had the chance to understand others emotionally. By variously feeling what others were feeling, we were directly motivated by their projects and concerns (Maibom, 2007). Furthermore, understanding other people and being aware of themselves helped them recognize their own needs in relation to others. Expressing their needs out loud through the playing sessions facilitated them to regulate and released their emotions safely.

The children experienced a sense of independence and self-acceptance in the final phase. The feeling of greatness and relief were the outcome of self acceptance. They tended to accept who they were in their families, at schools and even in society. They revealed the sense of having a good relationship with others. Accepting their significant role as a sibling, as a child, as a friend, and finally as an individual helped them play their own role in a greater sense. While accepting themselves, they also experienced a new range of emotions. They can 
identify and named based on their own insights and interestingly followed their feelings on a deeper level. As the final point, respondents experienced a sense of reality. They accepted their emotions and showed sadness toward finishing the CCPT process. Although they were sad as a termination indicator, they took it as their choice, and they felt responsible for it. Therefore, accepting their final emotion was their last psychosocial development through the CCPT process (refer to table 2 below).

Table 2: Summary of Participants' Social-Emotional Development through CCPT

\begin{tabular}{|c|c|c|c|}
\hline Themes & Initial phase & Middle phase & Final phase \\
\hline $\begin{array}{l}\text { Self- } \\
\text { development }\end{array}$ & $\begin{array}{l}\text { - self-concept } \\
\text { deficiency } \\
\text { - dependency }\end{array}$ & $\begin{array}{l}\text { - self-discovery } \\
\text { - self-awareness }\end{array}$ & $\begin{array}{l}\text { - self-acceptance } \\
\text { - independency }\end{array}$ \\
\hline $\begin{array}{l}\text { Emotional } \\
\text { development }\end{array}$ & $\begin{array}{l}\text { - external control } \\
\text { - releasing negative } \\
\text { emotion }\end{array}$ & $\begin{array}{l}\text { - sense of mastery } \\
\text { - tendency to be } \\
\text { disorganized and } \\
\text { forgetful }\end{array}$ & $\begin{array}{l}\text { - emotional } \\
\text { recognition } \\
\text { - emotional } \\
\text { regulation } \\
\end{array}$ \\
\hline $\begin{array}{l}\text { Social } \\
\text { development }\end{array}$ & $\begin{array}{l}\text { - interaction with } \\
\text { adults } \\
\text { - aware of others }\end{array}$ & $\begin{array}{l}\text { - empathy } \\
\text { - recognize self } \\
\text { - needs in relation } \\
\text { to others }\end{array}$ & $\begin{array}{l}\text { - relationship with } \\
\text { others }\end{array}$ \\
\hline
\end{tabular}

Overall, initial indicators such as a sense of inferiority, lack of security, dependency and lack of self-concept transmitted into the sense of industry, particularly in the middle phase as the heart of the CCPT process. Refugee children utilized their inner resources through the sessions besides accepting themselves while learning how to set realistic goal by overcoming perfectionism and accept themselves as an individual with a greater sense of self-concept.

\section{Conclusion}

The effect of play therapy on refugee children with the support of Erik Erikson $(1963,1968)$ psychosocial theory is underpinned by this paper's findings. Refugee children with anxiety revealed the crises of inferiority versus industry and role confusion versus self-identity (ego identity) through the CCPT process and how they experienced the process, aligned with the reported self-concept enhancement (Tydall-Lind, Landreth, \& Giprdano, 2001). Watson (2007) noted social skill improvements as another highlighted point supported by the refugee children's positive engagement in overcoming their conflicts and improved their social abilities and skills effectively in a safe and supportive environment. This study highlighted the effect of CCPT as a developmentally appropriate tool to enhance refugee children's psychosocial development.

Further research on the benefits of CCPT within the refugee population is vital and beneficial as the number of refugee children continues to grow. It would be practical to attempt a similar research project with children from different language and cultural backgrounds and, in other contexts, develop stronger outcomes. Further studies on the CCPT will serve a greater group of in-need refugee children, particularly exploring refugee children's developmental process with other disturbances, for instance, depression and post-traumatic stress disorders. This process helps to assist the refugee population in the area, which needs to be assisted more in the near future with the CCPT, especially in the post-pandemic Covid-19 period. As the final 
recommendation, utilizing the CCPT by the caseworkers, counsellors, teachers, community workers, and any other professionals related to refugee children would be a great assistance to the refugee children's psychosocial development and its counter effect on their adulthood and its secondary effect on the community and the society.

\section{Acknowledgement}

Special appreciation to the supervisory committee, Associate Prof. Dr Mariani Mansor, Prof. Dr Asnarulkhadi Abu Samah, Associate Prof. Dr Zainal Madon, the Sahabat Centre staff members, all participants, friends and family who facilitated this study process in many different ways.

\section{References}

Althy, A. L. (2005). Effects of a trained therapy dog in CCPT on children's biobehavioral measuresof anxiety. Master Dissertation. University of North Texas.

Barker, J., \& Weller, S. (2003). "Is it fun?" Developing children centred research methods. International Journal of Sociology and Social Policy, 23(1/2), 3358. https://doi.org/10.1108/01443330310790435

Bronstein, I., \& Montgomery, P. (2011). Psychological distress in refugee children: a systematic review. Clinical child and family psychology review, 14(1), 44-56. DOI: $10.1007 / \mathrm{s} 10567-010-00810$

Choy, G., Mclnerney, V., \& Jeffrey, P. L. (2006). Multidimensions of perfectionism and self concept in school aged children. In Proceedings of the 2006 Australian Association for Research in Education (AARE) Annual Conference, Adelaide, Australia.

Einarsdóttir, J. (2005). Playschool in pictures: Children's photographs as a research method. Early child development and care, 175(6), 523-541.

Erikson, E. H. (Ed.). (1963). Youth: Change and challenge. Basic books.

Erikson, E. (1968). Identity: Youth and Crisis. New York: Norton.

Halle, T. G., \& Darling-Churchill, K. E. (2016). Review of measures of social and emotional development. Journal of Applied Developmental Psychology, 45, 8-18.

Hands, C., Thomas, J., \& Legere, S. J. (2015). Refugee children in the UK. Occasional Review ofPediatrics and Child Health, 26(1), 37-41.

Landreth, G. (2002). Play therapy, the art of relationship. Professional Psychology Research and Practice, 33, 515-522.

Landreth, G. (2012). Play therapy: The art of the relationship (2nd ed.). New York: Routledge. Maibom, H. L. (2007). The Presence of Others. Journal of Philosophical Studies, 132(2), 161190. Retrieved from: https://doi.org/10.1007/s11098-004-0018-x

Rebok, G., Riley, A., Forrest, C., Starfield, B., Green, B., Robertson, J., \& Tambor, E. (2001). Elementary school-aged children's reports of their health: a cognitive interviewing study. Quality of Life Research, 10(1), 59-70.

Spence Children's Anxiety Scale. (ND). Retrieved from: https://www.scaswebsite.com/1_1_.html

Surin, T. S. (2016). Assessing developmental delay in refugee children. Faculty of medicine,University of Virginia, USA. Retrieved from: https://med.virginia.edu/familymedicine/wpcontent/uploads/sites/285/2017/02/Tamara-Saint-SurinDevelopmental-Delay-Refugee Children_Web.pdf

Tyndall-Lind, A., Landreth. G., \& Giordano, M. (2001). Intensive group play therapy with child witnesses of domestic violence. International Journal of Play Therapy, 10, 53-83. 
UNHCR. (2016). Report of the United Nations High Commissioner for refugees. Retrieved from: http://www.un.org/en/globalissues/briefingpapers/ refugees/

United Nations Children's fund. (2012). Retrieved from:

https://www.unicef.org/reports/stateworldschildren-2012

Watson, D. L. (2007). An early intervention approach for students displaying negative externalizing behaviors associated with childhood depression: A study of the efficacy of play therapy in the school. Capella University. Dissertation Abstracts International: Section A. Humanities and social sciences, 68(5), 1820. 